\title{
Evaluation of the Stability of Human Erythropoietin in Samples for Radioimmunoassay
}

\author{
K.-U. Eckardt ${ }^{1}$, A. Kurtz ${ }^{1}$, P. Hirth ${ }^{2}$, P. Scigalla ${ }^{2}$, L. Wieczorek ${ }^{2}$, and C. Bauer ${ }^{1}$ \\ ${ }^{1}$ Physiologisches Institut der Universität Zürich \\ ${ }^{2}$ Boehringer Mannheim GmbH
}

Summary. Radioimmunoassays for erythropoietin are limited so far to a few specialized laboratories and this requires transport and storage of samples. We therefore tested the stability of immunoreactive erythropoietin in serum and plasma samples obtained from a uremic and a nonuremic anemic patient. No significant change in the concentration of immunoreactive erythropoietin was found in either serum or plasma samples for up to 14 days of storage. This type of stability was observed no matter whether the samples were stored at room temperature, $4^{\circ} \mathrm{C}$, or $-20^{\circ} \mathrm{C}$. There was no difference between the estimates of erythropoietin in serum and heparinized plasma. Validity of the radioimmunoassay used in this study was demonstrated by parallelism of dilution curves of test specimens and the $2^{\text {nd }}$ International Reference Preparation for erythropoietin and by a close correlation between the immunoreactivity and the bioactivity of the hormone, as assessed in the same samples by the exhypoxic polycythemic mouse bioassay.

In conclusion the data obtained clearly indicate that the necessity of storage and transport of clinical samples does not limit the practicability of the radioimmunoassay for erythropoietin.

Key words: Erythropoietin - Stability - Radioimmunoassay - Polycythemic mouse bioassay - Recombinant DNA

Since recombinant human erythropoietin (rhEPO) became available for replacement therapy in pa-

Abbreviations: $\mathrm{BSA}=$ bovine serum albumin: $\mathrm{EPO}=$ erythropoietin; irEPO = immunoreactive erythropoietin; IRP = International Reference Preparation; hct = hematocrit; rhEPO=recombinant human erythropoietin; RIA = radioimmunoassay tients with certain forms of anemia $[5,9]$, the determination of erythropoietin (EPO) levels in body fluids has gained increasing clinical importance. However, radioimmunoassay kits are not yet commercially available and the limitation of EPO determinations to specialized laboratories necessitates storage and transport of the samples. This makes it important to know the stability of EPO in human samples. We therefore performed subsequent radioimmunological determinations of EPO for up to 14 days on serum and plasma samples which were stored at room temperature, $4^{\circ} \mathrm{C}$, or $-20^{\circ} \mathrm{C}$. The validity of RIA estimates was secured by determination of the biological activity of the same samples using an in vivo bioassay and by comparison of the slopes of dilution curves of test samples and the $2^{\text {nd }}$ International Reference Preparation (IRP) for EPO.

\section{Material and Methods}

\section{Antiserum to Erythropoietin}

Three New Zealand white rabbits were immunized with pure rhEPO ( $25 \mu \mathrm{g}$ per animal) according to standard methods. EPO for immunization was obtained from Genetics Institute, Boston, USA. During immunization two rabbits (\#1 and \#2) became severely anemic. Figure 1 shows the binding of radiolabelled recombinant human EPO to the different rabbit sera. It is obvious that rabbit \#1 produced a high titer of antibodies against EPO. The serum of this animal was used for radioimmunoassay.

\section{Radiolabelled Erythropoietin}

Human 3-( ${ }^{125}$ I)iodotyrosyl-erythropoietin, prepared by iodination of rhEPO using sodium 


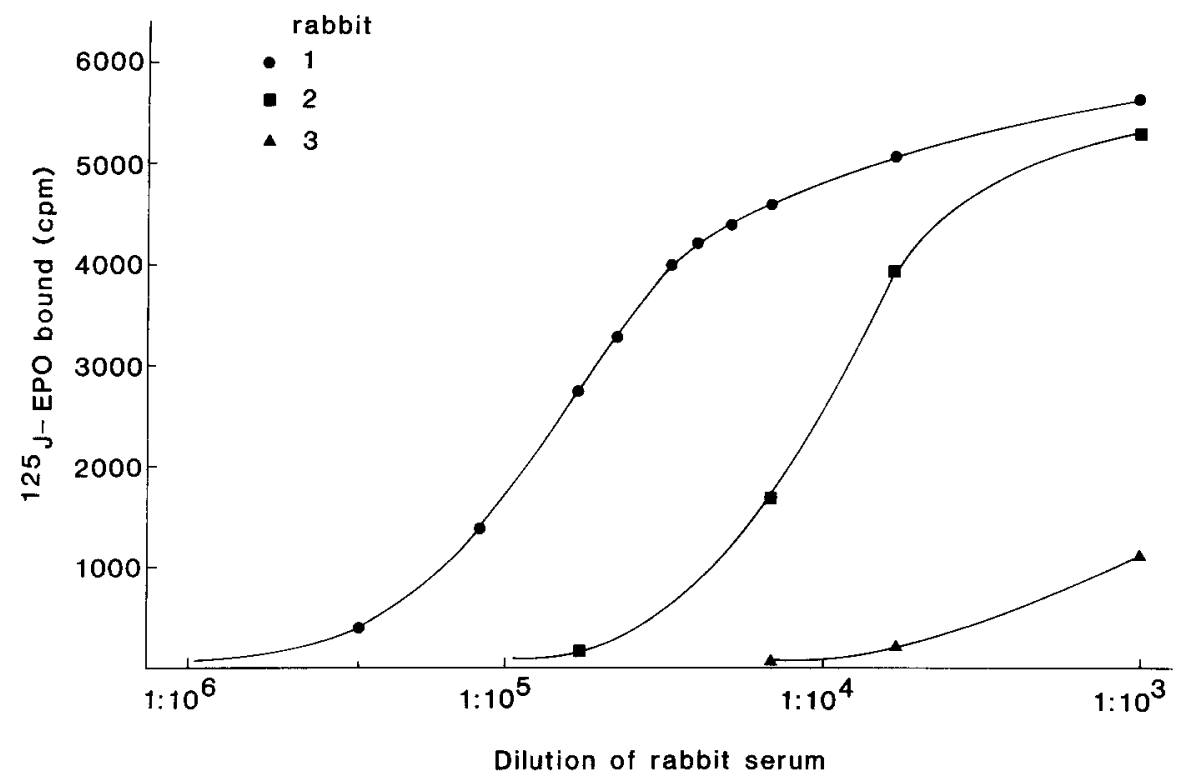

Fig. 1. Binding of recombinant human ${ }^{125} \mathrm{I}$-EPO to sera of rabbits immunized against EPO. $100 \mu$ serum at different dilutions was incubated with $100 \mu{ }^{125} \mathrm{I}$-EPO (containing $6000 \mathrm{cpm}$, i.e., $14 \mathrm{fmol} \mathrm{EPO}$ ) at $4^{\circ} \mathrm{C}$ overnight. EPO bound to antibodies was precipitated using $100 \mu \mathrm{l}$ (1 unit) of goat-anti-rabbit gammaglobulin

$\left({ }^{125} \mathrm{I}\right)$ iodide and chloramine $\mathrm{T}$, with a specific activity of 320 to $620 \mathrm{Ci} / \mathrm{mmol}$ was purchased from Amersham International (Amersham, England). A dilution containing $8 \times 10^{-11} \mathrm{~mol}$ radiolabelled $\mathrm{EPO} / 1$, corresponding to $6000-9000 \mathrm{cpm} / 100 \mu \mathrm{l}$, was prepared for use in the RIA.

\section{Erythropoietin Standard}

The $2^{\text {nd }}$ International Reference Preparation (IRP) of human urinary EPO was obtained from the Bureau of Biological Standards, National Institute of Medical Research, London, England, and was used as standard in the RIA and the bioassay.

\section{Radioimmunoassay for Erythropoietin}

Phosphate buffered saline, $\mathrm{pH} 7.5$, containing $0.1 \%$ bovine serum albumin (BSA) was used as diluent buffer for all reagents. All incubations were carried out at $4^{\circ} \mathrm{C}$.

Test Procedure. Aliquots of the following were combined in Eppendorf reaction cups: (a) $100 \mu 1$ of plasma, serum, or standard solutions (10-500 mU EPO/ml), (b) $100 \mu \mathrm{l}$ of diluted EPO antiserum (1:60000), and (c) $20 \mu 1$ of $30 \%$ BSA in PBS. After preincubation for $24 \mathrm{~h}, 100 \mu \mathrm{l}$ of radiolabelled EPO $\left(8 \times 10^{-15} \mathrm{~mol}\right)$ was added and tubes were incubated for another $24 \mathrm{~h}$. This delayed addition of the tracer resulted in increased steepness and a leftward shift of the log dose-re- sponse curve (see below) compared to the simultaneous addition of tracer with sample and antiserum $(50 \%$ binding at $65 \mathrm{mU} / \mathrm{ml}$ vs $250 \mathrm{mU} / \mathrm{ml}$ EPO) and thereby markedly increased sensitivity of the assay. This effect has been attributed to the formation of multivalent antigen-antibody complexes which are less likely to dissociate than univalent complexes [1]. After the incubation, separation of bound vs free ligand was accomplished using a secondary antibody technique. For this purpose $100 \mu l$ (1 unit) of goat-anti-rabbit-gammaglobulin (Calbiochem) and $100 \mu \mathrm{l}$ rabbit gammaglobulin (0.03 mg; Calbiochem) were added to the Eppendorf reaction cups to precipitate bound ligand. After incubation for $4 \mathrm{~h}$ the tubes were centrifuged at $9500 \mathrm{~g}$ for $15 \mathrm{~min}$. The supernatant was aspirated and the pellet counted for ${ }^{125} \mathrm{I}$ radioactivity.

Data Analysis. Data were expressed as percent of binding in the absence of unlabelled EPO. Calculations of unknowns were made on the basis of a standard log dose-response curve derived by the "spline-function" method (LKB Wallac Compu Gamma RIA program 1282-114); (Fig. 2, right panel).

Quality Controls. Protein bound radioactivity (as determined by adding $1 \mathrm{ml} \mathrm{10 \%} \mathrm{TCA} \mathrm{to} \mathrm{a} \mathrm{control}$ tube before the last incubation) was about $90 \%$ of the radioactivity added. The maximum amount of antibody-precipitable ${ }^{125} \mathrm{I}$ EPO (as determined 

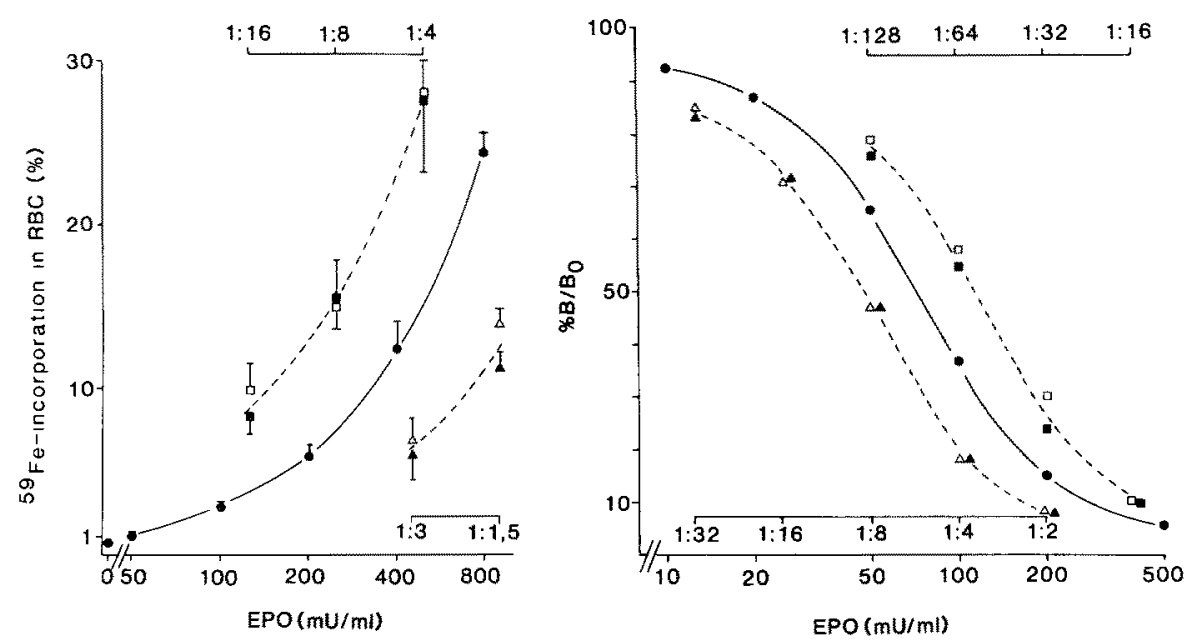

Fig. 2. Parallelism of erythropoietin-standard ( $2^{\text {nd }}$ IRP) dose-response curves and serial dilution curves of heparinized plasma (open symbols) and serum (closed symbols) from patient $1(\square:-)$ and patient $2(\Delta: \Delta)$ in the exhypoxic polycythemic mouse bioassay (left panel) and radioimmunoassay (right panel). Data in the bioassay indicate mean \pm S.E. of five animals each

using $100 \mu 1$ of diluent buffer instead of EPO standard) was approximately $55 \%$ of the total radioactivity added. Nonspecific binding (as determined using $100 \mu \mathrm{l}$ of diluent buffer instead of antiserum) was about $1 \%$ of the total radioactivity added.

The intraassay coefficient of variation (assessed by tenfold determination of a diluted serum sample with a mean of $70.4 \mathrm{mU} / \mathrm{ml}$ ) was $1.9 \%$. The interassay coefficient of variation of 20 assays was $7.5 \%$ and $6.8 \%$ for samples containing, respectively, a mean of $43.8 \mathrm{mU}$ and $168.5 \mathrm{mU}$ rhEPO.

\section{Bioassay for Erythropoietin}

The biological activity of EPO was measured by a modification of the exhypoxic polycythemic mouse bioassay [3]. Female ICR-strain mice (25-31 g) were exposed to intermittent (20-22 h/ day) normobaric hypoxia for 14 days, using a chamber that was gassed with a mixture of nitrogen and normal atmospheric air. The resulting oxygen concentration in the chamber was $7 \%-8 \%$. This regime renders animals severely polycythemic (hematocrit $80 \%$ on average) and leads to a subsequent inhibition of endogenous erythropoiesis.

On days 5 and 6 after removal from the chamber, assay animals were injected subcutaneously with $0.5 \mathrm{ml}$ of divided doses of standards or samples dissolved in $0.9 \% \mathrm{NaCl}$. On day 7 they were injected with $0.1 \mu \mathrm{Ci}^{59} \mathrm{Fe}$ i.p. Two days later heparinized blood was obtained by heart puncture for determination of hematocrit (het) and radioactive iron incorporation, which was calculated on the assumption of a blood volume of $7.5 \%$ body weight. The mean het in the assay described was
$66.4 \% \pm 5.46 \%$ (mean $\pm \mathrm{SD} ; n=105)$. Only mice having a het of $55 \%$ or higher were used for the calculations. EPO content of samples was determined on the basis of a standard log dose-response curve (Fig. 2, left panel), using the mean of five animals per point. In red blood cells of animals not receiving EPO ${ }^{59} \mathrm{Fe}$ incorporation averaged $0.47 \%$.

\section{Sample Collection and Storage}

Two male anemic patients served as blood donors. Patient 1 (hct $21 \%$ ) was suffering from aplastic anemia, patient 2 (hct $40 \%$ ) was on hemodialysis because of chronic renal failure due to polycystic kidney disease. Venous blood samples of these two patients were collected into either plain or heparincoated glass tubes and immediately kept on ice. Serum and plasma were separated in a refrigerated centrifuge and aliquotted under sterile conditions. The first RIA and estimation of EPO activity in the bioassay were performed within $2 \mathrm{~h}$ after collection of samples. The remaining aliquots were stored either at room temperature, at $4^{\circ} \mathrm{C}$, or frozen $\left(-20^{\circ} \mathrm{C}\right)$, and allowed to thaw only on the day of assay. Subsequent RIAs on serum and plasma stored under these different conditions were then performed daily up to day 6 and on days 9 and 14 after collection.

\section{Results}

The serum levels of EPO determined in the bioassay immediately after collection of the blood samples were $4200 \mathrm{mU} / \mathrm{ml}$ in patient 1 and $546 \mathrm{mU} / \mathrm{ml}$ 


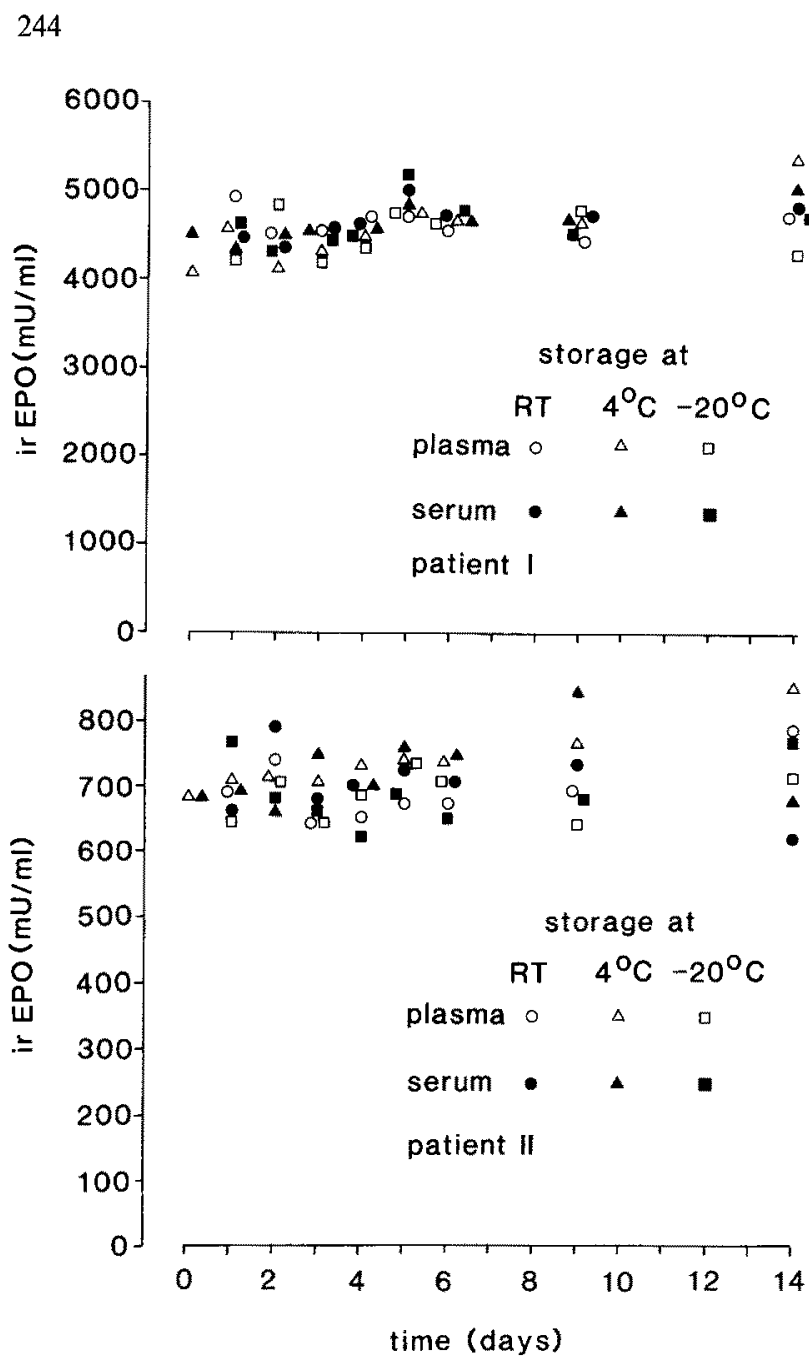

Fig, 3. Results of subsequent RIA determinations of EPO on serum and plasma samples stored under different conditions

in patient 2 , the corresponding estimates in plasma were $4000 \mathrm{mU} / \mathrm{ml}$ (patient 1) and $618 \mathrm{mU} / \mathrm{ml} \mathrm{(pa-}$ tient 2). Thus there was no significant difference between the biological activity of EPO in serum or plasma.

The results of the first radioimmunological estimations of the serum and plasma samples, which were performed shortly after collection, were $4520 \mathrm{mU} / \mathrm{ml}$ and $4068 \mathrm{mU} / \mathrm{ml}$ respectively in patient 1 and $677 \mathrm{mU} / \mathrm{ml}$ and $682 \mathrm{mU} / \mathrm{ml}$ respectively in patient 2 . The comparison between these results and the bioassay results shows a close correlation between the biological activity of the hormone and the immunoreactivity as assessed in the RIA, providing good evidence for the validity of the latter. As documented in Fig. 2, high specificity of both the bioassay and the RIA was further reflected by identical slopes of dilution curves of the samples and the $2^{\text {nd }}$ IRP of EPO, used as standard.

Figure 3 shows the results of the subsequent
K.-U. Eckardt et al.: Stability of Erythropoietin in Blood Samples

RIAs, performed on aliquots of serum or plasma stored under sterile conditions for various time intervals at different temperatures. It is obvious, that in samples from both patients there was no significant change of the estimates of immunoreactive (ir) EPO up to 14 days, no matter whether the samples were stored at room temperature, $4^{\circ} \mathrm{C}$, or $-20^{\circ}$. Furthermore, there was no significant difference between the estimates of irEPO in serum and plasma, either in individual assays, or comparing the means. The coefficient of variation of all determinations was $5.6 \%$ in patient 1 and $8.0 \%$ in patient 2 and this was within the normal limits of the assay.

\section{Discussion}

In order to determine the conditions that allow storage of human samples for valid determinations of irEPO, we tested the in vitro stability of irEPO in serum and plasma samples from a uremic and a nonuremic blood donor by subsequent RIAs.

First we found no significant difference between estimates of EPO in serum or heparinized plasma. This agrees with other investigators, who also compared RIA estimates of serum and plasma and found either equally no difference [4] or a minor reduction of the mean recovery in heparinized plasma [2] or EDTA plasma [7]. For clinical purposes it is important that heparinized plasma and serum can be used interchangeably in the EPORIA, as many candidates for EPO determinations are uremic patients, in whom blood samples are often collected at the occasion of hemodialysis and may contain various amounts of heparin.

Second, we found that storage of the samples for up to 14 days even at room temperature did not significantly affect the amount of immunoreactive EPO. This finding does, of course, not exclude any minor changes in the molecular structure of the hormone. However, it demonstrates, that EPO is certainly not subjected to rapid proteolysis, as has been shown for some polypeptide hormones in biological fluids [10]. This complements previous observations of a considerable stability of EPO under various other conditions, e.g., in response to heating [8], change in $\mathrm{pH}$, or exposure to various chemicals [6].

We conclude from the high stability of irEPO in serum and plasma, that no special precautions such as addition of protease inhibitors are required for the preservation of the hormone content and that samples do not necessarily have to be frozen, as long as assaying is guaranteed within 2 weeks of collection. 
Acknowledgement. We wish to thank Drs. Gmür and Keusch, Universitätsspital Zürich, for providing us with blood samples from their patients. We are grateful to Dr. Mary Cotes for her advice and to Dr. Patrick Storing from the National Bureau of Standards for providing us with the $2^{\text {nd }}$ International Reference Preparation for erythropoietin. The financial support of the Swiss National Science Foundation (Grant 3.023-0.84) and the Roche Research Foundation is gratefully acknowledged. One of us (K.-U.E.) acknowledges a fellowship from the Deutsche Forschungsgemeinschaft.

\section{References}

1. Chard T (1982) An introduction to radioimmunoassay and related techniques, 2nd edn. Elsevier Biomedical, Amsterdam, New York, Oxford, p 177

2. Cotes PM (1982) Immunoreactive erythropoietin in serum. Br J Haematol 50:427-438

3. Cotes PM, Bangham DR (1961) Bio-assay of erythropoietin in mice made polycythacmic by exposure to air at a reduced pressure. Nature 4793:1065-1067

4. Erslev AJ, Wilson J, Caro J (1987) Erythropoietin titers in anemic, nonuremic patients. J Lab Clin Med $109: 429-433$

5. Eschbach JW, Egrie JC, Downing MR, Browne JK, Adamson JW (1987) Correction of the anemia of end-stage renal disease with recombinant human erythropoietin. N Engl J Med 316:73-78
6. Espada J, Brandan NC, Dorado M (1973) Effect of chemical and enzymatic agents on the biological activity of erythropoietin. Acta Physiol Lat Am 23:193-201

7. Garcia JF, Ebbe SN, Hollander L, Cutting HO, Miller ME, Cronkite EP (1982) Radioimmunoassay of erythropoietin: circulating levels in normal and polycythemic human beings. J Lab Clin Med 99:624 635

8. Rambach WA. Alt HL, Cooper JAD (1957) The mode of action and nature of a heat stable plasma erythropoietic factor. Blood 12:1101-1113

9. Winearls CG, Pippard MJ, Downing MR, Oliver DO, Reid C, Cotes PM (1986) Effect of human erythropoietin derived from recombinant DNA on the anemia of patients maintained by chronic haemodialysis. Lancet $8517: 1175-1178$

10. Zyznar ES (1981) A rationale for the application of trasylol as a protease inhibitor in radioimmunoassay. Life Sci $28: 1861-1866$

Received: September 22, 1987

Returned for revision: November 20,1987

Accepted: December 7, 1987

Dr. Kai-Uwe Eckardt

Physiologisches Institut

Universität Zürich

Winterthurerstrasse 190

$\mathrm{CH}-8057$ Zürich/Switzerland 